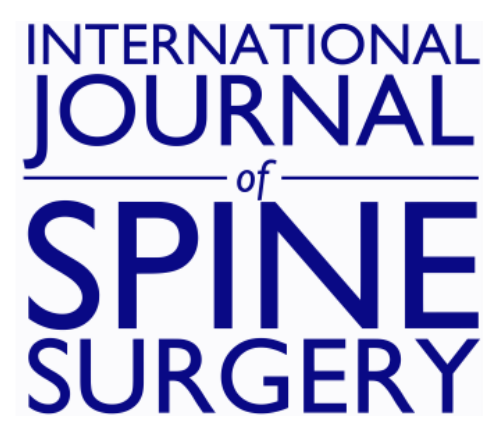

\title{
Anterior Fixation of Floating Facet Fractures in the Cervical Spine: A Prospective Case Series and Biomechanical Analysis
}

CHRISTOPHER CHAPUT, NATHAN B. HAILE, ADITYA M. MUZUMDAR, DAVID M. GLOYSTEIN, VASILIOS A. ZERRIS, PAUL J. TORTOLANI, MARK RAHM, MARK MOLDAVSKY, SURESH CHINTHAKUNTA and SAIF KHALIL

Int J Spine Surg 2018, 12 (1) 85-91

doi: https://doi.org/10.14444/5014

http://ijssurgery.com/content/12/1/85

This information is current as of April 26, 2023.

Email Alerts Receive free email-alerts when new articles cite this article. Sign up at: http://ijssurgery.com/alerts

The International Journal of Spine Surgery

2397 Waterbury Circle, Suite 1,

Aurora, IL 60504, Phone: +1-630-375-1432 


\title{
Anterior Fixation of Floating Facet Fractures in the Cervical Spine: A Prospective Case Series and Biomechanical Analysis
}

\author{
CHRISTOPHER CHAPUT, MD,${ }^{1}$ NATHAN B. HAILE, MD, ${ }^{2}$ ADITYA M. MUZUMDAR, MS,${ }^{3}$ DAVID M. \\ GLOYSTEIN, MD ${ }^{3}$ VASILIOS A. ZERRIS, MD, ${ }^{2}$ PAUL J. TORTOLANI, MD ${ }^{4}$ MARK RAHM, MD,${ }^{2}$ MARK \\ MOLDAVSKY, BS, ${ }^{5}$ SURESH CHINTHAKUNTA, MS, ${ }^{5}$ SAIF KHALIL, PhD ${ }^{5}$ \\ ${ }^{1}$ University of Texas Health Science Center at San Antonio, Texas, ${ }^{2}$ Baylor Scott \& White Health/Texas A\&M Health Science Center College of Medicine, \\ Temple, Texas, ${ }^{3}$ Carl R. Darnall Army Medical Center, Fort Hood, Texas, ${ }^{4}$ MedStar Union Memorial Hospital, Baltimore, Maryland, ${ }^{5}$ Globus Medical, Inc., \\ Audubon, Pennsylvania
}

\begin{abstract}
Background: Unilateral fractures involving complete separation of the lateral mass from the vertebra and lamina (floating lateral mass fractures) are a unique subset of cervical spine fractures. These injuries are at significant risk for displacement without operative fixation. Posterior fixation has proven to facilitate adequate fusion. However, there are few data supporting the clinical success of single-level anterior fixation.

Methods: Biomechanical evaluation of floating lateral mass fractures and a consecutive case series of patients with rotationally unstable floating lateral mass fractures treated with anterior fixation using an integrated cage-screw device with anterior plating (ICSD) was performed. The study comprised 7 fresh human cadaver cervical spines (C2-C7), and 11 patients with floating lateral mass fractures. Segmental flexibility testing evaluating axial rotation, flexion/extension, and lateral bending was performed in a cadaveric model after 2 types of single-level anterior fixation and 1 type of 2level posterior fixation. Eleven patients with a floating lateral mass fracture of the cervical spine underwent anterior fixation with an ICSD. Radiographs and clinical outcomes were retrospectively reviewed.

Results: Compared with the intact condition, posterior instrumentation significantly $(P<.05)$ reduced range of motion (ROM) in all 3 planes; anterior fixation with cervical plate and interbody spacer significantly reduced ROM in lateral bending only; and the ICSD significantly reduced ROM in flexion/extension and lateral bending. In the clinical arm, there were no long-term complications, subsidence $>2 \mathrm{~mm}$, failure of fixation, reoperation, pseudoarthrosis, or listhesis at final follow-up.

Conclusions: The addition of 2 screws placed through a cervical cage can improve anterior fixation in a human cadaveric model of floating lateral mass fractures. Early clinical results demonstrate a low complication rate and a high rate of healing with single-level anterior fixation using this technique.
\end{abstract}

Minimally Invasive Surgery

Keywords: floating lateral mass fracture, cervical fracture, anterior cervical fusion, posterior cervical fusion

\section{INTRODUCTION}

Unilateral fractures involving complete separation of the lateral mass from the vertebra and lamina (previously described as lateral mass fracture-separation, floating facet fractures, floating lateral mass, and unilateral lateral mass-facet fracture) are a unique subset of cervical spine fractures. ${ }^{1,2}$ The leading cause of these injuries is motor vehicle collisions, ${ }^{3,4}$ but the exact mechanism of injury has not been clearly established. These fractures often present with minimal displacement; however, there is nearly uniform consensus in the literature that these injuries are rotationally unsta- ble. ${ }^{1,2,4-9}$ Multiple authors have reported failure to maintain alignment when these fractures are treated in a cervical orthosis, with displacement rates up to $100 \%{ }^{1-14}$ Because of this risk, these fractures are now routinely treated with operative fixation at level 1 trauma centers. ${ }^{1-3,5-7,11,13-17}$

Floating lateral mass injuries in the cervical spine have historically been treated by posterior instrumentation (PI) and fusion of at least 3 vertebrae (2 motion segments), with good results. ${ }^{16}$ These injuries have also been successfully treated via anterior fixation with cervical plate and interbody spacer (SP), ${ }^{7}$ although failures have been reported with anterior fixation of only 1 motion 
segment. ${ }^{1,2}$ Recently, the authors have treated floating lateral mass fractures with anterior fixation of a single motion segment using a novel integrated cage-screw device in addition to standard anterior plating. Although many surgeons often use an anterior technique to address these fractures, there is a need for studies addressing the efficacy of these techniques. To our knowledge, no previous studies exist evaluating the kinematics of floating lateral mass injuries, or relevant fixation methods. The aims of this study were 2-fold. The first was to determine whether fixation can be improved by using an anterior approach with an integrated cagescrew device and anterior plating in a human cadaveric model of floating lateral mass fractures. The second was to present a case series of patients who had received this type of fixation and to determine the rate of loss of fixation and surgical complications.

\section{MATERIALS AND METHODS}

\section{Specimen Preparation}

Seven fresh human cadaver cervical spines (C2C7) were used. The specimens were harvested from 4 female and 3 male cadavers (mean age, $59 \pm 6$ years) and stored at $-20^{\circ} \mathrm{C}$ prior to thawing. The spines had been radiographed previously in the anteroposterior and lateral planes to ensure the absence of fractures, deformities, and any metastatic disease. The spines were carefully denuded of paravertebral musculature while the spinal ligaments, joints, and disc spaces were preserved. Each spine was potted proximally at $\mathrm{C} 2$ and distally at $\mathrm{C} 7$ in a 3:1 mixture of Bondo auto body filler (Bondo MarHyde Corp, Atlanta, Georgia) and fiberglass resin (Home-Solution All Purpose Bondo MarHyde). Plexiglas markers, each having 3 infrared light-emitting diodes, were secured rigidly to the anterior aspect of $\mathrm{C} 2, \mathrm{C} 3, \mathrm{C} 4, \mathrm{C} 5, \mathrm{C} 6$, and $\mathrm{C} 7$ vertebral bodies using bone screws to track its motion with an Optotrak Certus (NDI Inc., Waterloo, Ontario, Canada) motion analysis system. The location of the markers (denoting a rigid body) was approximately aligned sagittally along the curvature of the spine. The Optotrak Certus software was able to superimpose the coordinate systems of 2 adjacent vertebral bodies in order to inferentially determine the relative Eulerian rotations in each of the 3 planes.

\section{Flexibility Testing}

The specimen was fixed to the load frame of a 6 degree of freedom spine simulator, and a pure moment was applied to the $\mathrm{C} 2$ vertebra through servomotors. ${ }^{18,19}$ The specimen was maintained moist throughout the test by spraying it with $0.9 \%$ saline. All tests were carried out at room temperature of $25^{\circ} \mathrm{C}$. Each of the test constructs was subjected to 3 load-unload cycles in each of the physiologic planes generating flexion-extension, right-left lateral bending and right-left axial rotation load displacement curves. This was achieved by programming the motors to apply continuous moments in each physiologic plane. A typical load-unload cycle in the sagittal plane comprised neutral $\rightarrow$ full flexion $\rightarrow$ full extension $\rightarrow$ neutral (3 times). Data from the third cycle were considered for analysis. The design of the load frame enabled unconstrained motion of the spine in response to an applied load. There was no compressive preload applied on the specimen. A load control protocol was used to apply a maximum moment of \pm 1.5 $\mathrm{N} / \mathrm{m}$ at a rate of $1^{\circ} / \mathrm{sec}^{18-20}$ This describes the specified rate of motor movement in order to achieve the load limit of $1.5 \mathrm{~N} / \mathrm{m}$. The 3 -dimensional intervertebral rotation was obtained from the Optotrak Certus data files in the form of Euler angles $\left(^{\circ}\right)$ about the $\mathrm{x}-, \mathrm{y}-$, and $\mathrm{z}$-axes: $+\mathrm{Rx} /-\mathrm{Rx}$, $+\mathrm{Ry} /-\mathrm{Ry}$, and $+\mathrm{Rz} /-\mathrm{Rz}$ denoting flexion-extension, right-left axial rotation, and right-left lateral bending range of motion (ROM), respectively. The Euler sequence used in this study was xzy.

\section{Study Design}

Each of the 7 spines was initially tested in the intact state. Following intact testing, a right-sided floating lateral mass fracture was created at the C5C6 level. The injury model was designed to mimic a high-grade floating lateral mass pattern. This was achieved by first cleaning the specimen of the residual muscles while preserving the discoligamentous elements of the functional spinal unit. The laminofacet junction and pedicle on the right at $\mathrm{C} 5$ were then identified and these structures transected. The lateral mass was allowed to remain - floating in place, secured by the intact facet capsules. The interspinous ligament, supraspinous ligament, and the right side of the anterior longitudinal ligament with adjacent annulus were carefully dissected out of the specimen to simulate the fractured state. 
Paraspinal musculature had been removed previously. Testing was then repeated under the same loading conditions as for the intact state. After testing of the injured state, the following fixation constructs were tested in sequential order: 1) PI, with posterior lateral mass fixation and rods at $\mathrm{C} 4-$ C6 (screws at C4, C5, and C6 on the left side, and at $\mathrm{C} 4$ and $\mathrm{C} 6$ on the right side), with a cross connector at C5-C6; 2) spacer and anterior cervical plate (SP), a radiolucent interbody spacer with an anterior cervical plate at $\mathrm{C} 5-\mathrm{C} 6$; and 3 ) novel anterior fixation technique (ICSD), with an integrated spacer-plate and anterior cervical plate at C5-C6. Titanium polyaxial screws $(3.5 \mathrm{~mm}$ in diameter and $14 \mathrm{~mm}$ in depth) from the ELLIPSE OccipitoCervico-Thoracic Stabilization System (Globus Medical Inc., Audubon, Pennsylvania) were placed into the lateral masses at C4, C5, and C6 levels and connected by $3.5-\mathrm{mm}$-diameter titanium rods and a cross connector at C5-C6. After testing the PI construct, discectomy was carried out at the C5-C6 level in order to place the interbody constructs. The PROVIDENCE Anterior Cervical Plate (Globus Medical Inc.) and COLONIAL Spacer (Globus Medical Inc.) were used as the anterior cervical plate and interbody spacer respectively. COALITION ACDF (Globus Medical Inc.) was used as the integrated spacer-plate device. All the implants were properly sized, and the implantation was carried out as recommended by the respective surgical technique. Subsequent to intact testing, the instrumented constructs were subjected to the same load control protocol for flexibility testing as described above.

\section{Laboratory Data Analysis}

ROM data were normalized to intact $(100 \%)$. Statistical analysis was performed on raw data. Comparison of data was performed using repeatedmeasures analysis of variance for independent samples followed by Tukey post hoc analysis for multiple comparison procedures. ${ }^{21,22}$ Significance was accepted at $P \leq .05$.

\section{Clinical Data}

After approval was obtained from our Institutional Review Board, all Level I and II Trauma Team Activations $(\mathrm{n}=2292)$ seen from January 2008 to June 2011 were included from a prospective trauma database. A total of 194 patients $(8 \%)$ had a cervical spine fracture, and 12 of these patients had rotationally unstable fractures of the lateral mass and underwent fixation ( $6 \%$ of fractures). Of these patients, 1 was excluded after being lost to followup at 56 days, leaving a total sample size of $n=11$. The level of injury was confirmed with upright radiographs. Specifically, any spinal level with listhesis on a lateral radiograph of the cervical spine was identified as unstable. Patients with unstable fractures were treated with an integrated cage-screw device with anterior plating. Clinical and radiographic follow-up was then carried out. Metrics used were fusion grade, ${ }^{23}$ lordosis, range of motion, presence of subsidence $>2 \mathrm{~mm}$, and any postoperative complications.

\section{RESULTS \\ Flexion-Extension}

The injured condition had a significantly higher ROM $(245 \% \pm 100 \%, P<.05)$ compared with intact condition $(100 \%)$. All instrumented constructs (PI, SP, and ICSD) significantly $(P<.05)$ reduced $\mathrm{ROM}(11 \% \pm 5 \%, 31 \% \pm 22 \%$, and $18 \% \pm 9 \%$, respectively) compared with injured condition ROM $(245 \% \pm 100 \%)$. The PI $(11 \% \pm 5 \%)$ and $\operatorname{ICSD}(18 \% \pm 9 \%)$ constructs significantly reduced ROM compared with the intact condition (100\%). The SP $(31 \% \pm 22 \%)$ construct reduced ROM compared with the intact condition $(100 \%)$; however, no statistical significance was achieved.

\section{Lateral Bending}

All instrumented constructs (PI, SP, and ICSD) significantly $(P<.05)$ reduced ROM $(7 \% \pm 6 \%$, $51 \% \pm 46 \%$, and $27 \% \pm 15 \%$, respectively) compared with the injured $(195 \% \pm 76 \%)$ and the intact $(100 \%)$ conditions. The injured $(195 \% \pm 76 \%)$ condition had a higher ROM compared with the intact $(100 \%)$ condition; however, no statistical significance was achieved.

\section{Axial Rotation}

The injured condition had significantly higher $\operatorname{ROM}(P<.05)$ with axial rotation $(211 \% \pm 69 \%)$ compared with the intact condition $(100 \%)$. The PI $(13 \% \pm 8 \%)$ construct, the stiffest of the 3 constructs, significantly $(P<.05)$ reduced ROM compared with the intact $(100 \%)$ condition. The SP $(71 \% \pm 40 \%)$ and ICSD $(48 \% \pm 26 \%)$ constructs reduced ROM compared with the intact 


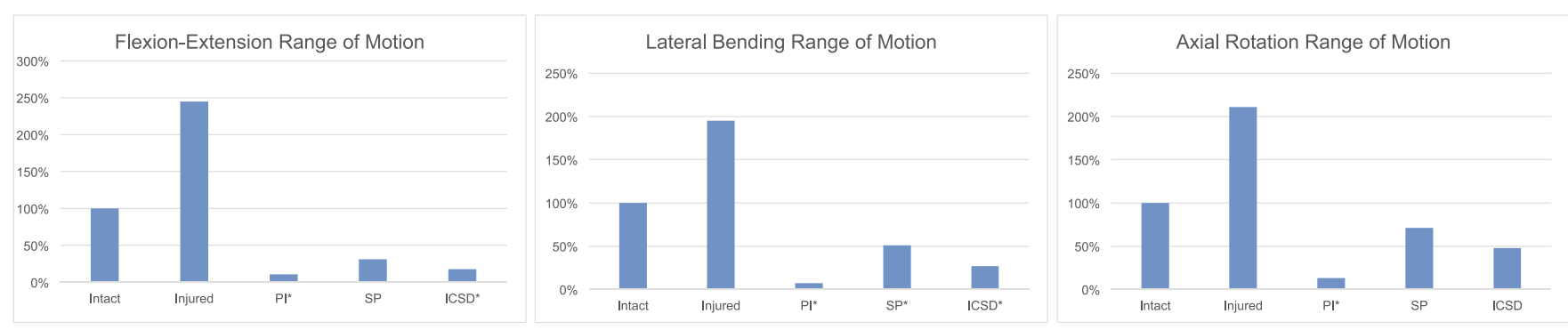

Figure 1. Percentage compared with intact state. *Statistical significance. Abbreviations: PI, posterior instrumentation; SP, interbody spacer; ICSD, integrated cagescrew device with anterior plating.

condition, without statistical significance. All instrumented constructs significantly $(P<.05)$ reduced ROM compared with the injured condition. Range of motion results are summarized in Figure 1.

\section{Clinical Results}

Eleven patients (average age, 34 years; range, 1580 years; median age, 36 years) with unilateral floating lateral mass fractures of the cervical spine were treated with the ICSD. Of the 11 patients, 4 smoked tobacco. Instrumentation was performed at the level of listhesis demonstrated on upright radiographs obtained either acutely or at the time of follow-up after initial treatment in a cervical collar. This included 1 fracture at $\mathrm{C} 4-\mathrm{C} 5,5$ fractures at C5-C6, 3 fractures at $\mathrm{C} 6-\mathrm{C} 7$, and 2 fractures at both $\mathrm{C} 5-\mathrm{C} 6$ and C6-C7. Average clinical follow-up was just under 1 year (347 days; range, 80-920 days; median, 328 days), whereas average radiographic follow-up was almost 18 months (509 days; range, 80-1399 days; median, 338 days). Fusion grade was identified as described previously by Carter et al. ${ }^{23}$ (Table 1). The results are as follows: 8 patients had a fusion grade of 1 , and 2 patients had a fusion grade of 2. Of the 4 patients who smoked tobacco, 3 had a fusion grade of 1 and 1 had a fusion grade of 2 . In the nonsmokers, 5 had a fusion grade of 1 and 1 had a fusion grade of 2 . The average lordosis was $4.08^{\circ}$ (range, $1^{\circ}-6.3^{\circ} ; \mathrm{SD}, 1.87^{\circ}$ ). Of the 11 patients, 8 were found to have $<2^{\circ}$ of motion at the level of fixation. ROM was not determined in 2 patients because of a lack of radiographic follow-up. Fusion grade, lordosis, and ROM were not determined in 1

Table 1. Computed tomography fusion grade as described by Carter et al. ${ }^{18}$

Grade 3

Grade 4

Solid bilateral fusion with bridging bone Solid unilateral fusion with bridging bone Defects in fusion mass bilaterally Definite graft resorption patient because of poor radiographic quality secondary to body habitus. The only complication reported was dysphagia in 1 patient, which quickly resolved. Subsidence $>2 \mathrm{~mm}$ was not found in any patient. At final follow-up, there were no instances of failure of fixation, reoperation, pseudoarthrosis, or significant adjacent segment listhesis. These results are summarized in Table 2.

\section{DISCUSSION}

Cervical spine injuries are a common injury in the polytraumatized patient $(5.37 \%),{ }^{24}$ occurring in $11.2 \%$ of motorcycle collisions and $14.1 \%$ of motor vehicle collisions. ${ }^{25}$ A subset of cervical spine fractures, floating lateral mass fractures, are rotational injuries that require operative fixation to prevent displacement. Previously, fixation was achieved most reliably through posterior instrumentation and fusion. This approach provides excellent stability; however, the logistics of prone positioning can be problematic, especially in patients with extremity fractures (up to $10 \%$ of patients with cervical spine fractures $\left.{ }^{26}\right)$. Additionally, infection

Table 2. Clinical data.

\begin{tabular}{|c|c|c|c|c|}
\hline Age (y) & $\begin{array}{c}\text { Tobacco } \\
\text { Use }\end{array}$ & $\begin{array}{l}\text { Fusion } \\
\text { Grade }\end{array}$ & $\begin{array}{c}\text { Lordosis } \\
\left({ }^{\circ}\right)\end{array}$ & $\begin{array}{c}\text { Range } \\
\text { of Motion } \\
\left({ }^{\circ}\right) \\
\end{array}$ \\
\hline 23 & Positive & 1 & 6.1 & $<2$ \\
\hline 19 & Negative & 1 & 3.5 & $\begin{array}{l}\text { Not determined } \\
\text { due to lack } \\
\text { of follow-up }\end{array}$ \\
\hline 24 & Positive & 1 & 2.8 & $<2$ \\
\hline 36 & Negative & 1 & 6.3 & $\begin{array}{l}\text { Not determined } \\
\text { due to lack } \\
\text { of follow-up }\end{array}$ \\
\hline 50 & Positive & 1 & 1 & $<2$ \\
\hline 24 & Negative & 1 & 6.2 & $<2$ \\
\hline 58 & Negative & 1 & 2.1 & $<2$ \\
\hline 15 & Negative & 2 & 5 & $<2$ \\
\hline 39 & Negative & $\begin{array}{l}\text { Unclear due } \\
\text { to body } \\
\text { habitus }\end{array}$ & $\begin{array}{l}\text { Unclear due } \\
\text { to body } \\
\text { habitus }\end{array}$ & $\begin{array}{l}\text { Unclear due to } \\
\text { body habitus }\end{array}$ \\
\hline 51 & Negative & 1 & 3 & $<2$ \\
\hline 49 & Positive & 2 & 4.8 & $<2$ \\
\hline
\end{tabular}




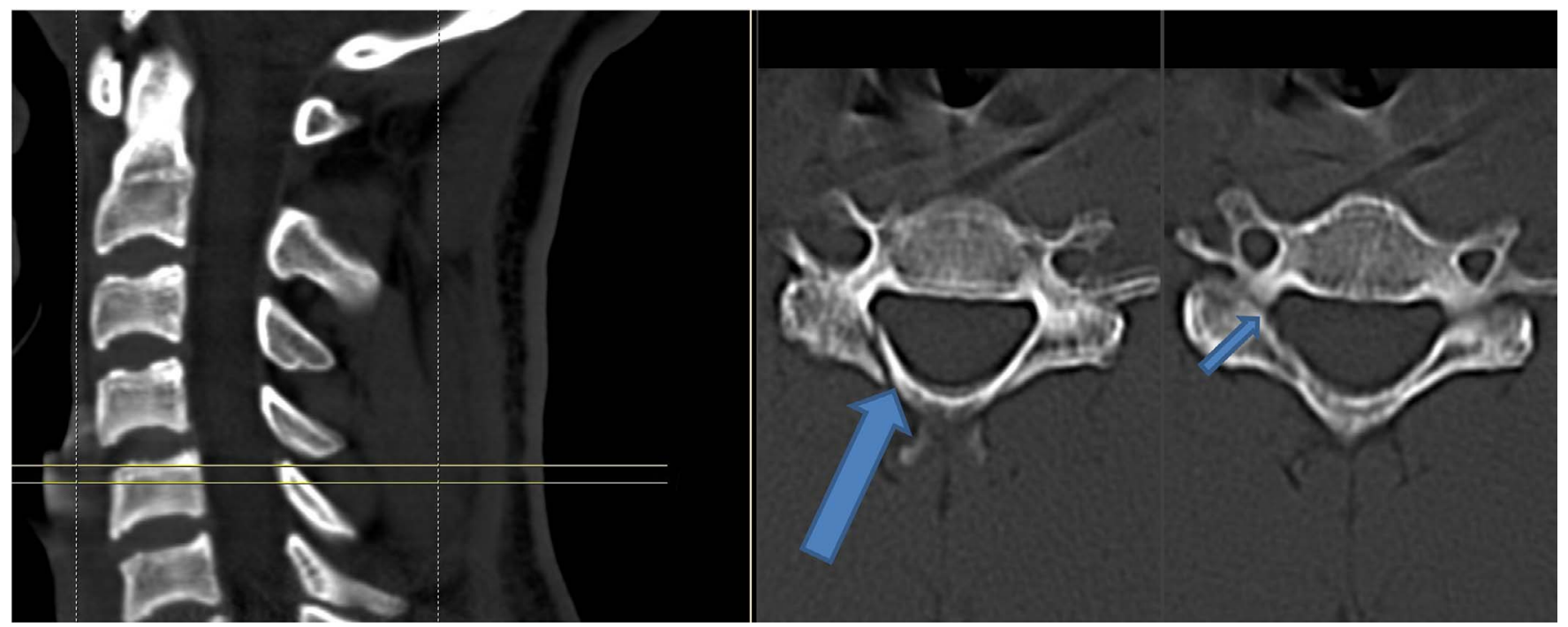

Figure 2. Computed tomography scan demonstrating trace listhesis at C4-C5, with a floating lateral mass injury involving the right C5 lamina (big arrow) and right C5 pedicle (small arrow). Based on this supine study, it is unclear whether this 2-level injury pattern represents true instability at both levels.

rates are higher in the posterior approach compared with an anterior approach. ${ }^{15}$ Treatment in the supine position decreases operative time and limits the risk of hemodynamic instability and the possibility of neurologic progression associated with prone positioning. ${ }^{27}$ Because of these advantages, many surgeons routinely treat these patients with anterior fixation of 1 or 2 motion segments. However, significant failure rates $(80 \%-83 \%)$ have been reported with single-level anterior instrumentation and fusion in these injuries. ${ }^{1,2}$ In an attempt to avoid this complication our treatment protocol includes obtaining upright radiographs of the cervical spine to aid in determining the level(s) of rotational instability. Our clinical results suggest that while floating lateral mass fractures are, by definition, a 2-level injury, they commonly result in clinically significant instability at only 1 level. This is demonstrated by the presence of listhesis at only 1 level on upright radiographs. We saw no adjacent segment instability or instrumentation failure with this approach (Figures 2 and 3). It should be noted however, that like the patients in the study by Lee et al., ${ }^{1}$ these patients did not have severe neurologic deficits, and their
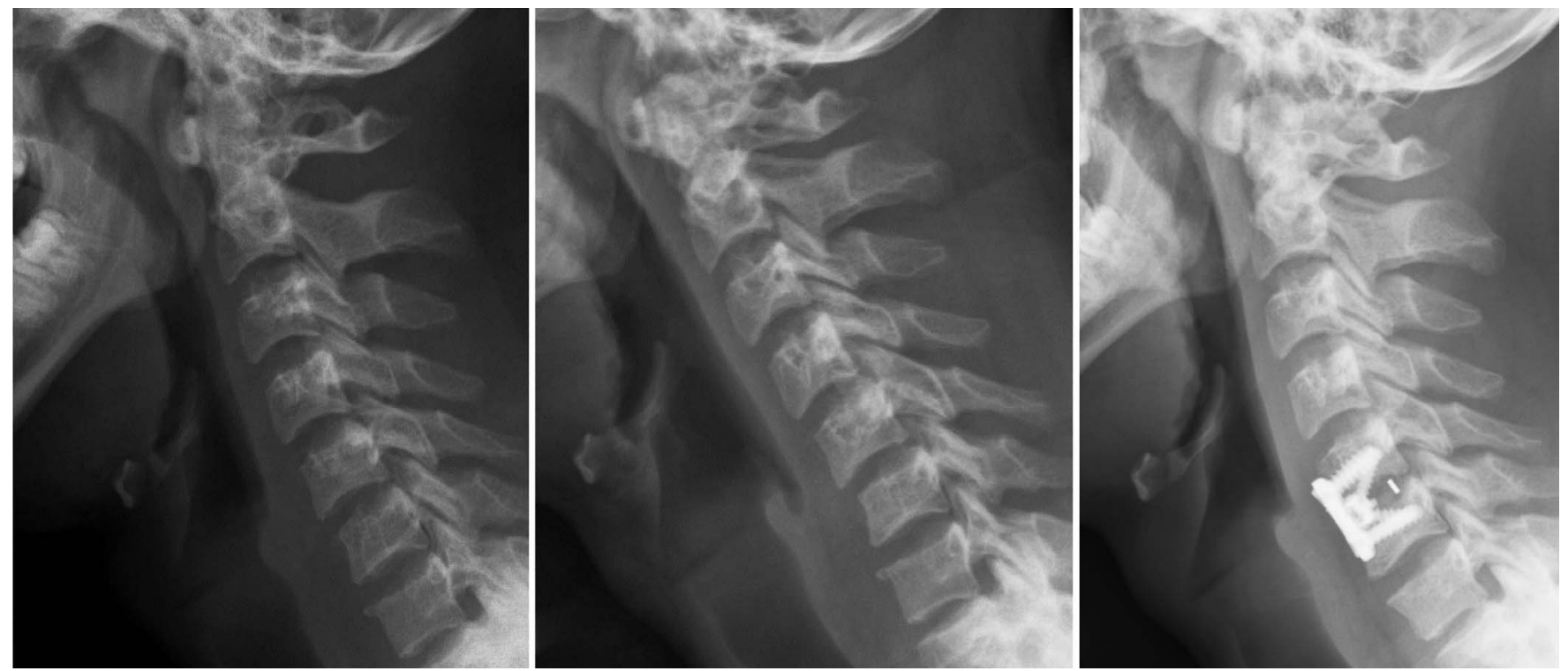

Figure 3. The patient was mobilized in a collar, and an upright lateral radiograph was obtained (left), which showed no significant listhesis. However, the lateral radiograph at 1-week follow-up showed kyphosis and listhesis at C5-C6, with trace listhesis at C4-C5 (middle). One year postoperatively, the trace listhesis at C4-C5 resolved with anatomic fixation of only the progressive instability at C5-C6 (right). 
injuries did not preclude rapid mobilization in a cervical orthosis. This facilitated upright radiographs, which determined the level of operative fixation. Furthermore, patients in whom an anatomic reduction cannot be obtained should not be considered for single-level anterior fixation of any type. As Lee et al. ${ }^{1}$ point out, "horizontalization" of the lateral mass occurs either acutely or gradually as a patient is mobilized. If this rotation of the lateral mass inferiorly in the sagittal plane is not reduced anatomically, or if ligamentous injury is seen at the adjacent segment by magnetic resonance imaging, 2segment anterior or posterior fixation is required. Additionally, patients with highly displaced fracture patterns that suggest 360-degree ligamentous disruption or fractures involving the vertebral body endplates should not be considered for single-level anterior fixation of any type. Failure to recognize these fracture characteristics may lead to increased rates of fixation failure, pseudoarthrosis, or kyphosis.

In our biomechanical testing, all 3 instrumentation techniques significantly stabilized the cervical spine compared with the injured state (simulated unilateral floating lateral mass fracture). The novel technique using the integrated cage-screw device significantly $(P=.05)$ increased segmental stability in 2 of the 3 testing modes (flexion-extension and lateral bending) compared with the intact state, whereas the more traditional interbody spacer and an anterior plate construct increased stability in only 1 testing mode (lateral bending). Posterior segmental instrumentation improves segmental stability in all 3 planes of motion. However, this technique requires an additional level of fixation, as well as more difficulty with positioning and a more morbid surgical approach. ${ }^{15}$ In our series, 11 patients with a cervical floating lateral mass injury were treated with single-level anterior fixation with an integrated cage-screw device. Average clinical and radiographic follow-up was less than 1 year, and no loss of fixation, adjacent segment instability, or reoperation occurred. Fusion grade and recreation of segmental lordosis were adequate in all patients. It should be noted that all patients received an integrated cage-screw device, as well as an anterior plate and screw construct. The integrated cage-screw device was not used in isolation, and this type of construct is not recommended for significant instability when used as a "stand-alone."

Our study does have limitations. Because of the rarity of floating lateral mass injuries, the sample size of only 11 patients in the case series is quite small. Regarding the biomechanical portion of the study, it is a load-controlled, segmental flexibility study using cadaver models in which bone, disc and ligamentous cuts were made in a controlled setting and the skin and musculature have been removed. Thus, this model characterizes only acute stability and does not allow any comments to be made regarding longerterm stability (eg, testing after cyclical load). Although the floating lateral mass injury was recreated as accurately as possible, the lack of these soft tissues and the sharp nature of the osteotomies are admittedly different than the mechanism that is required to produce such injuries in vivo.

\section{CONCLUSION}

In the treatment of unilateral floating lateral mass fractures, posterior instrumentation and fusion provides the most stable fixation. However, our findings suggest that the addition of 2 screws through a cervical cage-screw device can improve anterior fixation in a human cadaveric model of floating lateral mass fractures. Early clinical results show a low complication rate and a high rate of healing with this technique.

\section{REFERENCES}

1. Lee SH, Sung JK. Unilateral lateral mass-facet fractures with rotational instability: new classification and a review of 39 cases treated conservatively and with single segment anterior fusion. J Trauma. 2009;66:758-767.

2. Manoso MW, Moore T, Agel J, Bellabarba C, Bransford RJ. Floating lateral mass fractures of the cervical spine. Spine (Phila Pa 1976). 2016;41(18):1421-1427.

3. Hadley MN, Fitzpatrick BC, Sonntag VK, Browner $\mathrm{CM}$. Facet fracture-dislocation injuries of the cervical spine. Neurosurgery. 1992;30(5):661-666.

4. Halliday AL, Henderson BR, Hart BL, Benzel EC. The management of unilateral lateral mass/facet fractures of the subaxial cervical spine: the use of magnetic resonance imaging to predict instability. Spine. 1997;22(22):2614-2621.

5. Aarabi B, Mirvis S, Shanmuganathan K, et al. Comparative effectiveness of surgical versus nonoperative management of unilateral, nondisplaced, subaxial cervical spine facet fractures without evidence of spinal cord injury. $J$ Neurosurg Spine. 2014;20(3):270-277.

6. Bucholz RD, Cheung KC. Halo vest versus spinal fusion for cervical injury: evidence from an outcome study. $J$ Neurosurg. 1989;70(6):884-892.

7. Lifeso RM, Colucci MA. Anterior fusion for rotationally unstable cervical spine fractures. Spine. 2000;25(16):20282034.

8. Vaccaro AR, Hulbert RJ, Patel AA, et al. The subaxial cervical spine injury classification system: a novel approach to recognize the importance of morphology, neurology, and 
integrity of the disco-ligamentous complex. Spine. 2007;32(21):2365-2374.

9. White AA, Southwick WO, Panjabi MM. Clinical instability in the lower cervical spine: a review of past and current concepts. Spine. 1976;1:15-27.

10. Anderson PA, Moore TA, Davis KW, et al. Cervical spine injury severity score: assessment of reliability. $J$ Bone Joint Surg Am. 2007;89(5):1057-1065.

11. Dvorak MF, Fisher CG, Aarabi B, et al. Clinical outcomes of 90 isolated unilateral facet fractures, subluxations, and dislocations treated surgically and nonoperatively. Spine. 2007;32(26):3007-3013.

12. Shapiro SA. Management of unilateral locked facet of the cervical spine. Neurosurgery. 1993;33(5):832-837.

13. Levine AM, Mazel C, Roy-Camille R. Management of fracture separations of the articular mass using posterior cervical plating. Spine. 1992;17(Suppl 10):S447-S454.

14. Kalayci M, Cagavi F, Acikgoz B. Unilateral cervical facet fracture: presentation of two cases and literature review. Spinal Cord. 2004;42(8):466-472.

15. Kwon BK, Fisher CG, Boyd MC, et al. A prospective randomized controlled trial of anterior compared with posterior stabilization for unilateral facet injuries of the cervical spine. $J$ Neurosurg Spine. 2007;7(1):1-12.

16. Kotani Y, Abumi K, Ito M, Minami A. Cervical spine injuries associated with lateral mass and facet joint fractures: new classification and surgical treatment with pedicle screw fixation. Eur Spine J. 2005;14(1):69-77.

17. Jeanneret B, Gebhard JS, Magerl F. Transpedicular screw fixation of articular mass fracture-separation: results of an anatomical study and operative technique. J Spinal Disord. 1994; 7(3):222-229.

18. Moon SM, Ingalhalikar A, Highsmith JM, Vaccaro AR. Biomechanical rigidity of an all-polyetheretherketone anterior thoracolumbar spinal reconstruction construct: an in vitro corpectomy model. Spine J. 2009;9(4):330-335.

19. Gabriel JP, Muzumdar AM, Khalil S, Ingalhalikar A. A novel crossed rod configuration incorporating translaminar screws for occipitocervical internal fixation: an in vitro biomechanical study. Spine J. 2011;11(1):30-35.

20. Goel VK, Panjabi MM, Patwardhan AG, Dooris AP, Serhan H. Test protocols for evaluation of spinal implants. $J$ Bone Joint Surg Am. 2006;88(Suppl 2):103-109.

21. Panchal RR, Matheis EA, Gudipally M, Hussain MM, Kim KD, Bucklen BS. Is lateral stabilization enough in thoracolumbar burst fracture reconstruction? A biomechanical investigation. Spine J. 2015;15(10):2247-2253.

22. Gedet P, Haschtmann D, Thistlethwaite PA, Ferguson SJ. Comparative biomechanical investigation of a modular dynamic lumbar stabilization system and the Dynesys system. Eur Spine J. 2009;18(10):1504-1511.

23. Carter JD, Swearingen AB, Chaput CD, Rahm MD. Clinical and radiographic assessment of transforaminal lumbar interbody fusion using HEALOS collagen-hydroxyapatite sponge with autologous bone marrow aspirate. Spine $J$. 2009;9(6):434-438.

24. Qi X, Yang DL, Qi F, Zhang QH, Wang JP. Statistical analysis on 2213 inpatients with traffic injuries from January 2003 to September 2005 in Ningbo city. Chin J Traumatol. 2006;9(4):228-233.

25. Robertson A, Branfoot T, Barlow IF, Giannoudis PV. Spinal injury patterns resulting from car and motorcycle accidents. Spine. 2002;27(24):2825-2830.

26. Chu D, Lee $\mathrm{YH}$, Lin $\mathrm{CH}$, Chou $\mathrm{P}$, Yang NP. Prevalence of associated injuries of spinal trauma and their effect on medical utilization among hospitalized adult subjectsa nationwide data-based study. BMC Health Serv Res. 2009;9:137.

27. Prasarn ML, Horodyski M, Dubose D, et al. Total motion generated in the unstable cervical spine during management of the typical trauma patient: a comparison of methods in a cadaver model. Spine. 2012;37(11):937-942.

Disclosures and COI: This study was approved by the Baylor Scott \& White Health Institutional Review Board. CC reports travel support and provision for writing assistance, medicines, equipment, or administrative support, as well as consulting, royalties, and research support from Globus; research support from Pfizer; and consulting for LinkSpine. AMM reports employment and stock/stock options at Globus Medical Inc. PJT reports consultancy for Globus Medical Inc. and Spinology, grants from Globus Medical Inc., and royalties from Globus Medical Inc. MR reports travel support from Globus Medical Inc., royalties from Spinesmith, speaking and/or teaching arrangements with Medtronic, and research support from K2M. MM reports research support from Globus Medical Inc. SC reports stock ownership and research support from Globus Medical Inc. SK reports employment at Globus Medical Inc. NBH, DMG, and VAZ report no conflicts.

Corresponding Author: Christopher Chaput, MD, University of Texas Health Science Center at San Antonio, 7703 Floyd Curl Drive, San Antonio, TX 78229. Phone: (210) 567-5133; Email: chaput@ uthscsa.edu.

Published 30 March 2018

This manuscript is generously published free of charge by ISASS, the International Society for the Advancement of Spine Surgery. Copyright (C) 2018 ISASS. To see more or order reprints or permissions, see http://ijssurgery.com. 